\title{
BRIEF
}

\section{Student Pharmacists' Perceptions of Male Faculty Teaching Female-Specific Sex and Gender Health Topics}

\author{
Herman Joseph Johannesmeyer, PharmD, Nhu Quyen Dau, PharmD \\ Marshall B. Ketchum University, College of Pharmacy, Fullerton, California \\ Submitted September 7, 2020; accepted March 9, 2021; published June 2021.
}

\begin{abstract}
Objective. The primary objective of this study was to assess perceptions of second year pharmacy students regarding predominantly male faculty instructing them regarding female physiology, pathophysiology, and gender health topics.

Methods. A cross-sectional survey was administered to second year pharmacy students at a small, private, non-profit college of pharmacy at the conclusion of their women's health integrated pharmacotherapeutics course. Students were asked to rate their level of agreement with various statements using a five-point Likert scale on which $1=$ strongly disagree and $5=$ strongly agree.

Results. Forty-seven students completed the survey ( 26 female and 21 male). The students indicated high agreement with statement: "Prior to the lectures, I felt comfortable having male faculty teach the majority of women's health topics" (median $=5, \mathrm{IQR}=4-5$ ). Students also indicated neutrality towards the statement: "The gender of the instructor is of importance in the didactic instruction of women's health topics" (median $=3, \mathrm{IQR}=1-3$ ). No significant differences were observed regarding student gender.

Conclusion. Pharmacy students were generally amenable to male faculty teaching female-specific sex and gender health topics. This pattern was observed in both male and female students.
\end{abstract}

Keywords: women's health, gender dynamics

\section{INTRODUCTION}

Didactic instruction on obstetric and gynecologic $(\mathrm{OB} /$ GYN) disorders is an essential component of the Doctor of Pharmacy curriculum. The American College of Clinical Pharmacists (ACCP) believes contraception, menopausal symptoms, and drug therapy considerations during pregnancy and lactation to be areas in which pharmacy students should be able to provide patient-centered care immediately upon graduation. ${ }^{1}$ Other topics, including sexual dysfunction, infertility, and painful menstruation, should be included in pharmacy school curricula as well. Complete delivery of some of these topics requires instruction on intra-vaginal medication use and counseling regarding the patient's sexual activities.

Conversations around sexual intercourse and disorders pertaining to the reproductive system are often difficult to address and in some cultures and groups considered taboo at least relative to discussion of other, less personal health topics such as hypertension or dyslipidemia. ${ }^{2,3}$ A 2015 study found that $32 \%$ of Americans

Corresponding Author: Herman Joseph Johannesmeyer, Marshall B. Ketchum University, College of Pharmacy, 2575 Yorba Linda Blvd., Fullerton, CA 92831. Tel: 714-872-5726. Email: hjohannesmeyer@ketchum.edu considered sexual contact outside of marriage to be "morally abhorrent," with $4 \%$ of respondents believing that culturally pervasive promiscuity was the country's greatest moral defect. These issues call attention to the sometimes uncomfortable prospects of addressing these topics within the classroom. Though there is no definitively right way to teach a clinical topic within a pharmacy curriculum, it is sensible for special consideration to be given to the delivery of content on women's health topics as they are frequently focused on the genitourinary tract or secondary sex organs. Such considerations may need to be considered when designing a didactic course that addresses sexual health to prevent distress in some students. This may also be applicable to men's health topics; however, the focus of our study was on the appropriateness, as perceived by pharmacy students, of male faculty teaching women's health topics.

Some might assume that pharmacy schools would have female faculty deliver the majority of didactic instruction on women's health for several reasons. Recent reports indicate that most of the pharmacy academy is female. In the 2020-2021 academic year, $51.3 \%$ of fulltime pharmacy faculty members identified as female. ${ }^{4}$ Furthermore, in the 2018-2019 academic year, 62\% of doctor of pharmacy degree recipients identified as 


\section{American Journal of Pharmaceutical Education 2021; 85 (6) Article 8383.}

female. ${ }^{5}$ The social faux pas of men providing unsolicited advice in a condescending manner to a woman that already has a strong working knowledge of the subject in question has come under increased scrutiny in recent years. This situation would be avoided entirely if a female instructor were to provide the didactic instruction of women's health. ${ }^{6,7}$ Additionally, in practice, studies have shown that chaperones are used more frequently when an intimate examination of a patient is performed by a provider of the opposite sex. ${ }^{8-10}$ However, chaperones are recommended to be present for any intimate physical examination regardless of the gender of the patient or clinician. ${ }^{11,12}$ The reasons behind this are varied and include to provide legal protection, to decrease patient embarrassment, and to decrease the risk of sexual impropriety. Finally, while no previous research was identified that explicitly demonstrated a definite student preference regarding the gender of a women's health instructor in higher education, participants of a female sexual health empowerment curriculum stated a decided preference for having a female instructor. ${ }^{13}$

The question of whether pharmacy students find a male instructor teaching them about intimate treatments for female patients embarrassing or improper remains unanswered. This report describes an instance in which, as a result of preestablished faculty workload delegation, male faculty were assigned to deliver most of the female-specific sex and genderhealth topics in a pharmacy curriculum at a small, private, not-for-profitcollege of pharmacy in Southern California. During the first professional year, all of the curriculum on female reproductive anatomy and physiology is taught by male faculty. During the second professional year, $85 \%$ of the women's health integrated pharmacotherapeutics course is taught by male faculty. The instructor of the $\mathrm{OB} /$ GYN pharmacotherapeutics course is an acute care internal medicine pharmacist by training and maintains an acute care practice site. Thus, this faculty was designated to teach the course out of curricular necessity and not specifically by clinical expertise.

To date, no study has evaluated student perceptions of the sex and gender of the instructor delivering pharmacy lectures on women's health. The purpose of this study was to assess the perceptions of second-year pharmacy students of male faculty members instructing them in female physiology, pathophysiology, and gender-specific health topics in an integrated pharmacotherapeutics course. Secondary objectives included determining whether students perceived the time allocated to the subject to be appropriate and identifying characteristics that make students more or less amenable to male faculty teaching female-specific sex and gender health topics within the integrated pharmacotherapeutics course.

\section{METHODS}

This study was a cross-sectional survey given to second year pharmacy students at Marshall B. Ketchum University College of Pharmacy in Fullerton, California, at the conclusion of the men's and women's health integrated pharmacotherapeutics course. Students were eligible for enrollment in the study if they met the following criteria: completed the required women's health component of the integrated pharmacotherapeutics course and attended class on the day of survey distribution. Students were excluded if they preferred to not complete the survey. Participation in the anonymous survey was voluntary and not linked to any point-generating class activities. The study was reviewed and approved by the university's institutional review board.

After second year pharmacy students completed their women's health curriculum, study investigators distributed a subject consent form explaining the survey and the survey instrument to each member of the class, verbally advised students that their completion of the survey was entirely optional and confidential and would have no impact on their grade for the course. Students were instructed to place the completed survey instrument in an opaque envelope. After this, the study investigators left the room while the subjects completed the survey. Study investigators returned to the room to secure the opaque envelopes with the enclosed surveys immediately after completion. Survey questions one through 10 and students' responses are presented in Table 1. Students were also invited to write strengths or specific points of improvement that were needed to the delivery of sex-specific female health topics in an optional free response section at the bottom of the survey instrument.

Central tendencies were calculated as medians with interquartile ranges (IQR). Subgroup comparisons of levels of agreement to survey questions were analyzed using the Mann-Whitney $U$ test when comparing responses between male and female students. To compare responses by ethnicity, student responses were consolidated to groups consisting of Asian, white, and other/no response. The Kruskall-Wallis test was used to detect differences on the basis of ethnicity.

Comparison between subject level of agreement and age were made using a Spearman correlation.

\section{RESULTS}

Forty-seven of 50 students enrolled in the women's health integrated pharmacotherapeutics course completed the 10-question survey on the last day of class. The majority of students were female $(n=26,55 \%)$ and of Asian $(n=27$, $57.4 \%)$ or Caucasian $(n=8,17 \%)$ descent. Additional demographic details are listed in Table 2. 


\section{American Journal of Pharmaceutical Education 2021; 85 (6) Article 8383.}

Table 1. Pharmacy Students' Responses to a Survey Regarding Perceptions About Male Faculty Members Teaching FemaleSpecific Sex and Gender Health Topics

\begin{tabular}{|c|c|c|}
\hline Survey Question & $\begin{array}{c}\text { Level of } \\
\text { Agreement }(\mathrm{IQR})^{\mathrm{a}}\end{array}$ & $\begin{array}{c}\text { Median Female vs } \\
\text { Male Response (IQR) }\end{array}$ \\
\hline $\begin{array}{l}\text { 1. Prior to the lectures, I felt comfortable having male } \\
\text { faculty teach the majority of women's health topics. }\end{array}$ & $5(4-5)$ & $5(4-5)$ vs $5(4.3-5)$ \\
\hline $\begin{array}{l}\text { 2. After the lectures, I feel comfortable that male faculty } \\
\text { taught the majority of women's health topics. }\end{array}$ & $5(4.5-5)$ & $5(5-5)$ vs $5(5-5)$ \\
\hline $\begin{array}{l}\text { 4. After the lectures, I feel comfortable that female faculty } \\
\text { taught a small portion of women's health topics. }\end{array}$ & $5(4-5)$ & $5(4-5)$ vs $5(4-5)$ \\
\hline $\begin{array}{l}\text { 5. I would feel more comfortable in class if more male } \\
\text { faculty taught women's health topics. }\end{array}$ & $3(3-3)$ & $3(3-3)$ vs $3(3-3.8)$ \\
\hline $\begin{array}{l}\text { 6. I would feel more comfortable in class if more female } \\
\text { faculty taught women's health topics. }\end{array}$ & $3(3-3.5)$ & $3(3-3)$ vs $3(3-4)$ \\
\hline $\begin{array}{l}\text { 8. The gender of the instructor is of importance in the } \\
\text { didactic instruction of women's health topics. }\end{array}$ & $3(1-3)$ & $2(1-3)$ vs. $3(2-3)$ \\
\hline $\begin{array}{l}\text { 9. Female pharmacy faculty were/would be better } \\
\text { instructors of women's health topics because they are } \\
\text { more aware of patient concerns. }\end{array}$ & $3(2-3)$ & $2(1.3-3)$ vs $3(2.3-3.8)$ \\
\hline $\begin{array}{l}\text { 10. The distribution of time on various topics was } \\
\text { appropriate (eg, hours spent on hormone replacement } \\
\text { therapy, contraception, menstrual cycle disorders, etc). }\end{array}$ & $4(3-5)$ & $4(3-5)$ vs $4.5(4-5)$ \\
\hline
\end{tabular}

Abbreviations: IQR = interquartile range

${ }^{\text {a }}$ Responses based on a Likert scale ranging from $1=$ strongly disagree and $5=$ strongly agree

Overall students showed high levels of agreement in response to questions inquiring about their comfort with male faculty teaching female-specific sex and gender health topics (questions 1-4). Students also demonstrated neutrality in response to questions inquiring whether the women's health integrated pharmacotherapeutics course could be improved by greater female instructor participation and/or whether student or instructor gender is important in the provision of female-specific sex and gender health topics (questions 5-9). Survey responses are included in Table 1.

Completing the women's health integrated pharmacotherapeutics course appeared to have no impact on student comfort with male faculty teaching female-specific sex and gender health topics. No statistical difference was detected between questions 1 and 2 regarding change in comfort with male faculty teaching the majority of female-specific sex and gender health topics before vs after the course (5[4-5] vs 5[4.5-5], $p=.43$ ). Additionally, no statistical difference was detected between responses to questions 3 and 4 inquiring whether students were comfortable with female faculty teaching only a small portion of the course (5 [4-5] vs 5 [4-5], $p=.87$ ). Furthermore, there was no indication that the students believed the course would be improved by including specifically male or female instructors (questions 5 vs 6,3 (3-3) vs 3 [3-3.5], $p=.61$ ).

When comparing the responses between male and female students, no significant differences were found between male and female students' responses to any of the 10 questions (all $p$ values $>.05$ ). However, a trend towards significance was noted on question 9. Numerically, more male students agreed that female pharmacy faculty would be better instructors for the course because they would be more aware of patient concerns (3 [2.25-3.75] vs 2 [1.25-3], $p=.09)$. However, more female students disagreed with this statement. No significant differences were identified when comparing responses by student ethnicity.

The only significant correlation illustrated by student age was decreasing agreement with increasing age in response to the statement that the number of hours dedicated to various topics within the course were appropriate $(p=.04$, Spearman rho $=-.324)$. This negative correlation was more consistent in women than in men (female students, Spearman rho=-.399; male students, Spearman rho-.134). 


\section{American Journal of Pharmaceutical Education 2021; 85 (6) Article 8383.}

Table 2. Demographic Information for Pharmacy Students Who Participated in a Survey Regarding Their Perceptions About Male Faculty Members Teaching Female-Specific Sex and Gender Health Topics $(\mathrm{N}=47)$

\begin{tabular}{ll}
\hline & \multicolumn{1}{c}{$\mathbf{n}(\mathbf{\%})$} \\
\hline Gender & \\
Female & $26(55.3)$ \\
Male & $18(38.3)$ \\
No Response & $3(6.4)$ \\
Race & \\
Asian & $27(57.4)$ \\
White & $8(17.0)$ \\
Hispanic & $1(2.1)$ \\
Other & $2(4.3)$ \\
Mixed & $2(4.3)$ \\
American & $1(2.1)$ \\
Indian & \\
No Response & $6(12.8)$ \\
Variable & Median (IQR) \\
Age, y & $27(25-30)$ \\
\hline
\end{tabular}

\section{DISCUSSION}

Students in the present study were largely accepting of male faculty providing didactic instruction on femalespecific sex and gender health topics. Furthermore, students were generally ambivalent when questioned about whether they perceived the gender of the faculty member teaching these topics as important. These results stand in mild contrast to previous reports showing that healthcare practitioners believe that female $\mathrm{OB} / \mathrm{GYN}$ specialists may be more adept practitioners and that patients may prefer female OB/GYN practitioners. ${ }^{14-16}$ This could be due to the didactic pharmacy curriculum not involving direct physical assessment for these topics.

Varying perceptions about the importance of sex and gender in the context of teaching have been reported from the student, faculty, and patient perspectives. In one 2003 study, 602 generalist physician faculty were surveyed about their confidence and attitudes in teaching women's health procedures and treatment concepts. ${ }^{14}$ The primary findings of that study highlighted the differences in comfort with precepting students and the relative priority of various women's health topics between general internal medicine physicians and family practice physicians. ${ }^{14}$ Reported within the study, female physicians believed more frequently than male physicians that female patients prefer female physicians to perform their pelvic examinations (69\% vs $23 \%$ ). Additionally, female physicians believed more frequently than male physicians that women were better at performing pelvic examinations $(30 \%$ vs $9 \%)$ because they were more cognizant of patient concerns and hesitations. Additionally, multiple studies evaluating patient perceptions of student physician involvement during OB/GYN care visits showed that patients are more comfortable with female student involvement than male student involvement during the assessment and physical examination. ${ }^{15,16}$ Based on these data, we believed it was reasonable to extrapolate that female pharmacy students would think female pharmacy instructors would be better at delivering instruction on women's health topics and better understand health outcomes. These results contrast with the findings described in our report as female students in our study disagreed with this statement while more male students agreed with it. Interestingly, more male students agreed that female pharmacy faculty would be better instructors on women's health topics. This was an unexpected finding and further research may help elucidate whether this was an anomaly or evidence of a larger trend in student perceptions that should be further investigated.

In addition to the above studies, a 2003 survey among Swedish physician faculty reinforced the concept that there are varying opinions between male and female clinical academicians with regard to the importance of sex and gender in clinical and instructional roles. ${ }^{17}$ In this survey, respondents were asked to rate their level of agreement with five statements on a visual analogue scale. One question in that survey was, "My own gender is of importance in clinical tutoring." Female physicians displayed a higher level of agreement with this statement than male physicians $(p<.001)$.

This again contrasts with what was identified in the cohort of student pharmacists included in this report as our students' opinions were notably neutral regarding the importance of the gender of faculty teaching health care education. Reasons for the differences between this study and our report may include societal differences between Sweden and the United States, changes in societal attitudes from 2003 to the present, and again, fundamental differences in training and job descriptions of pharmacists and physicians.

The authors of this report were intrigued by the negative correlation between age and agreement that the didactic time allotment for topics within the course was appropriate. More time in this course is allotted to issues that affect women during their child-bearing years, including pregnancy, lactation, contraception, and primary dysmenorrhea. Comparatively, somewhat less time is allotted to pharmacotherapeutic indications that occur later in life, such as menopause and urinary incontinence. The authors postulate that ayounger female student would bemore personally invested in many of the topics discussed in this course than an older female student, though no published literature was identified that provides objective evidence that this speculation is true. 


\section{American Journal of Pharmaceutical Education 2021; 85 (6) Article 8383.}

There are a number of confounders that could explain why the results in this report contrast with data from previous reports. One reason for this and a limitation to our study was the small sample size included. This study was conducted at a small, private college of pharmacy. Further data collection was planned but was precluded by the coronavirus disease 2019 pandemic interrupting on-campus activities. Another limitation includes the nature of the data collection performed. Previous reports have indicated that students in higher education may harbor subconscious gender biases and expectations that may not necessarily be captured when a student is directly asked about gender dynamics. ${ }^{18}$ A previous study from 2016 analyzed third year medical student post-clerkship surveys on preceptor instructional effectiveness in surgery, $\mathrm{OB} / \mathrm{GYN}$, internal medicine, and pediatrics rotations. ${ }^{19}$ Male preceptors received statistically higher scores in all rotations including OB/GYN (4.4 vs 4.3 on a 5-point Likert scale, $p=.026$ ). While this may indirectly support the observation in our investigation that health professions students do not find a male instructor teaching on intimate female issues inappropriate, the fact that this pattern was observed across all rotations in the 2016 study led the investigators to attribute these differences primarily to gender biases placed on male and female instructors. ${ }^{19}$ A final limitation of our study to consider concerns the instructor of this course, his specific delivery style, and involvement in this study. The primary author of this study was the instructor of the women's health course and, thus, students may have been influenced to respond positively knowing their instructor would read the survey forms. Additionally, the specific style of delivery, level of empathy in discussing these topics, and tact may have influenced the results.

Future research in this area might include administering survey questions 1-4 as a true pre- and post-survey as opposed to a retrospective pre- and post-survey. Additionally, similar questions could be posed regarding malespecific sex and gender health topics to see if attitudes vary. A similar survey could be given to first year pharmacy students to assess their perceptions of a male faculty teaching all of the women's health pathophysiology course. Finally, these same questions could also be asked of members of the Academy to gauge their perception of the appropriateness of male faculty teaching female-specific sex and gender health topics.

\section{CONCLUSION}

Second year student pharmacists enrolled in this study were largely supportive of male faculty teaching the majority of female-specific sex and gender health topics in an integrated pharmacotherapeutics course.
Participants were neutral with regard to the importance of the gender of an instructor who was teaching women's health topics. This finding suggests that male faculty may be integrated into the didactic teaching of women's health topics without inciting student distress. Further research may help elucidate whether male pharmacy students perceive female faculty to be more attuned to female patient needs.

\section{ACKNOWLEDGMENTS}

The authors would like to acknowledge Heidi Tran, Crystal Mathos, and Yipu Chen for their assistance with data collection.

\section{REFERENCES}

1. Schwinghammer TL, Crannage AJ, Boyce EG, et al. The 2016 ACCP Pharmacotherapy Didactic Curriculum Toolkit. Pharmacotherapy 2016;36(11):e189-e194.

2. Morini M. Same-sex marriage and other moral taboos: cultural acceptances, change in American public opinion and the evidence from the opinion polls. European Journal of American Studies. 2017;11(3). 3. Traumer L, Jacobsen MH, Laursen BS. Patients' experiences of sexuality as a taboo subject in the Danish healthcare system: a qualitative interview study. Scand J Caring Sci. 2019;33(1):57-66.

4. American Association of Colleges of Pharmacy. Pharmacy Demographics and Salaries Reports. https://www.aacp.org/research/ institutional-research/pharmacy-faculty-demographics-and-salaries. Accessed June 2, 2021.

5. American Association of Colleges of Pharmacy. Academic Pharmacy's Vital Statistics. https://www.aacp.org/article/academicpharmacys-vital-statistics. Accessed June 2, 2021.

6. Stempler F. The Ithacan. Mansplaining affects the educational progress for women at IC. https://theithacan.org/news/mansplainingaffects-the-educational-progress-for-women-at-ic/. Accessed June 2, 2021.

7. Conner B, McCauliff K, Shue C, Stamp GH. Explaining mansplaining. Women \& Language. 2018;41(2):143-167.

8. Richard B, Orest M, Janette C-S, Paul S, Nicola C. Patients' views on and professionals' use of chaperones during intimate examinations in primary health care: a review. Qual Prim Care. 2007(6):337-344. 9. Modgil V, Barratt R, Summerton DJ, Muneer A. Chaperone use amongst UK urological surgeons - an evaluation of current practice and opinion. Ann R Coll Surg Engl 2016;98(4):268-269.

10. Fan VC, Choy HT, Kwok GY, et al. Chaperones and intimate physical examinations: what do male and female patients want? Hong Kong Med J 2017;23(1):35-40.

11. Intimate examinations and chaperones. London: General Medical Council; 2013.

12. Sexual Misconduct: ACOG Committee Opinion, Number 796. Obstet Gynecol 2020;135(1):e43-e50.

13. Pickett ML, Wickliffe J, Emerson A, Smith S, Ramaswamy M. Justice-involved women's preferences for an internet-based sexual health empowerment curriculum. Int J Prison Health. 2019;16(1):3844.

14. Dixon JG, Bognar BA, Keyserling TC, et al. Teaching women's health skills: confidence, attitudes and practice patterns of academic generalist physician. J Gen Intern Med. 2003;18(6):411-418. 


\section{American Journal of Pharmaceutical Education 2021; 85 (6) Article 8383.}

15. Coppola LM, Reed KL, Herbert WN. Comparison of patient attitudes and provider perceptions regarding medical student involvement in obstetric/gynecologic care. Teach Learn Med. 2014; 26(3):239-243

16. Carmody D, Tregonning A, Nathan E, Newnham JP. Patient perceptions of medical students' involvement in their obstetrics and gynaecology health care. Aust N Z J Obstet Gynaecol. 2011;51(6): 553-558.
17. Risberg G, Johansson EE, Westman G, Hamberg K. Gender in medicine - an issue for women only? a survey of physician teachers' gender attitudes. Int J Equity Health. 2003;2(1):10.

18. Sprague J, Massoni K. Student evaluations and gendered expectations: what we can't count can hurt us. Sex Roles 2005;53:779-793.

19. Morgan HK, Purkiss JA, Porter AC, et al. Student evaluation of faculty physicians: gender differences in teaching evaluations. Journal of Women's Health (2002). 2016;25(5):453-456. 